\title{
Comparison of Canal Transportation and Centering Ability of K- files, the ProGlider file and G-Files: A Micro-Computed Tomography Study of Curved Root Canals
}

Farzana Paleker, BChD, MSc ${ }^{*}$ and Peet van der Vyver, BChD, $\mathrm{MSc}^{*}$

"From the Department of Odontology, School of Dentistry, Faculty of Health Sciences, University of Pretoria, Pretoria, South Africa

\section{Highlights}

- Micro-CT comparisons of centering ability and apical canal transportation of 3 glide path enlargement techniques in curved root canals of extracted mandibular molars.

- K-files were least centered and caused more transportation.

- ProGlider displayed superior centering ability.

- ProGlider and G-Files caused significantly less transportation than K-files.

\begin{abstract}
Introduction: The purpose of this study was to compare centering ability and apical canal transportation of K-files (KF), ProGlider (PG) and G-Files (GF) after glide path enlargement in curved canals using micro-CT. Methods: 30 canals each were randomly assigned to KF; GF and PG. Teeth were scanned before and after glide path enlargement to compare centering ability at three levels: $1 \mathrm{~mm}$ (D1) and $7 \mathrm{~mm}$ (D7) from the apical foramen and at the point of maximum root curvature (Dmc). Transportation was assessed in 8 directions at D1. Results: KF were significantly less centered than both NiTi groups at D1. At Dmc PG exhibited a significantly more centered enlargement than both GF and KF, which were significantly similar. At D7, PG was significantly more centered than KF but there were no significant differences between GF and KF or between PG and GF ( $\mathrm{p}<0.016)$. KF exhibited significantly more canal transportation at D1 than the NiTi groups $(\mathrm{p}<0.05)$. Conclusion: NiTi files cause less transportation than KF. At D1 KF were less centered than both NiTi files. PG remained more centered at Dmc and D7.
\end{abstract}




\section{Keywords}

Glide path enlargement, G-Files, ProGlider, centering ability, transportation, microcomputed tomography

\section{Significance}

A poorly centered glide path system increases the risk of apical canal transportation and other procedural errors along the canal resulting in further challenges. Results show that the NiTi rotary glide path enlargement files used in this study maintain the original anatomical root canal outline, and respect the location of the apex. The ProGlider file displayed superior centering ability and transported fewer apices making it potentially more suitable for curved canals in the clinical situation.

\section{Introduction}

The endodontic glide path is defined as a smooth tunnel from the orifice of a root canal to the physiologic terminus of a root that allows for predictable cleaning and shaping to follow $(1,2)$. A glide path that is smooth and centered from its orifice to the physiologic terminus will enable further shaping of the root canal with nickeltitanium (NiTi) instrumentation because it allows for the tip of the first rotary instrument to follow (3-5). A successful glide path reduces torsional stress, increases the life span of shaping instruments, and reduces procedural errors such as ledge formation, canal transportation, and perforation (1, 4-7). An established glide path allows for predictable radicular cleaning and shaping to follow and therefore must be the starting point of all root canal preparations.

Glide path enlargement can be carried out with pre-curved stainless steel K-files or NiTi glide path files. The advantages of using stainless steel hand K-files include improved tactile sensation; appreciation of anatomical curvatures; decreased risk of file fracture; negotiation of canal blockages and decreased cost $(1,8,9)$. The disadvantages of enlarging a glide path with hand instruments include operator and hand fatigue; increased enlargement time; risk of canal aberrations with the use of larger file sizes and greater change to the original canal anatomy and increased apical extrusion of debris (10). 
Studies have shown that glide path enlargement with NiTi files is faster and causes less procedural errors than hand K-files (11-14). This been attributed to the superior flexibility of these files (14). G-Files (Micro-Mega, Besançon, France) are 3\% tapered nickel-titanium glide path files with non-cutting tips. The G1 and G2 file has ISO tip sizes of 12 and 17 respectively. ProGlider (Dentsply/Maillefer, Ballaigues, Switzerland) is a single mechanical glide path file with a semi-active tip and progressive tapers from $2 \%$ to $8 \%$ over its length. This file is manufactured using Mwire technology and has a square cross-section with an ISO tip of 16.

The assessment of endodontic instrumentation has been made possible with microcomputed tomography (micro-CT). A recent study by Pasqualini et al (12) used micro-CT to examine curved root canals following glide path preparation. This modality is a non-destructive analytical method that enables researchers to examine root canals in three-dimensions $(15,16)$. Micro-CT provides superior resolution quality to that of computed tomography but can only be carried out on extracted teeth.

The aim of this micro-CT study was to compare the canal centering ability and apical root canal transportation of pre-curved stainless steel K-files, the ProGlider file and G-Files after glide path enlargement in curved root canals of extracted human mandibular molars.

\section{Materials and Methods}

\section{Selection of teeth}

Fifty mandibular molars with previously untreated intact mesial roots and closed apices were chosen for this study from a pool of human teeth extracted for reasons unrelated to this study. A total of ninety separate MB and ML root canals with curvatures of $25^{\circ}$ to $30^{\circ}$ were selected from the fifty molars and randomly assigned to three experimental groups of 30 canals each for glide path enlargement. Curvatures were determined using the technique described by Schneider (17).

\section{Micro-CT Analysis}

The selected teeth were mounted on a stable support and scanned before instrumentation using the XTH 225 ST micro-focus X-ray computed tomography 
system (Nikon Metrology, Leuven, Belgium) (Scan 1). This system has a spatial resolution capability of $0.001-0.006 \mathrm{~mm}$ (18). A 5-axis sample manipulator is installed in the lead-lined cabinet of the system and is completely controlled by an acquisition computer. A series of sequential two-dimensional (2D) X-ray images are captured as the object is rotated through $360^{\circ}$. These images are then reconstructed to generate a 3D volumetric representation of the object. The accurate rotation movement allows for up to 4000 or more 2D tiff-format projections that are reconstructed into a 3D volume. Reconstruction parameters are optimized automatically so that the quality of the scan is not dependent on the qualitative opinion of the operator. The final product from a reconstruction is a $3 \mathrm{D}$ volume file that can be directly imported in VGStudioMax visualization software (19).

\section{Specimen Preparation}

Standard endodontic access cavities were prepared and working length for each canal was determined.

\section{Group KF: Glide Path Enlargement using Pre-Curved Stainless Steel K-files}

Manual pre-flaring with pre-curved stainless steel K-files (Dentsply/Maillefer) in the following sequence: ISO\#10, \#15, and then \#20 to working length $(\mathrm{n}=30)$.

\section{Group GF: Glide Path Enlargement using the G-File system}

A reproducible glide path was manually established with a pre-curved \#10 stainless steel K-file before the glide paths were enlarged using G1 and G2 files ( $n=30)$.

\section{Group PG: Glide Path Enlargement using the ProGlider file}

A reproducible glide path was manually established with a pre-curved \#10 stainless steel K-file before the glide paths were enlarged using the ProGlider file $(n=30)$.

Glyde Root Canal Conditioner (Dentsply/Maillefer) was used as a chelator in all canal preparations and Jik (3\% sodium hypochlorite) (Rekitt Benckiser, South Africa (Pty) Ltd., Elandsfontein, Gauteng, South Africa) was used for canal irrigation after the use of each file. 
The teeth were scanned after instrumentation (Scan 2). VGStudioMax software enabled merging of the pre-instrumentation 3D images (Scan 1) and postinstrumentation 3D images (Scan 2) for each tooth. Canals from Scan 2 were superimposed over corresponding canals from Scan 1 to measure the changes following instrumentation. VGStudioMax measurement instruments allow for distance (actual or $\min / \max$ ), angles, or polylines to be measured. The $\mathrm{min} / \mathrm{max}$ tool is capable of measuring distances like maximum movements automatically (19).

\section{Evaluation}

Changes in root canal diameter were measured at three different levels:

- $\mathrm{D} 1=1 \mathrm{~mm}$ from the apical foramen

- $\quad \mathrm{Dmc}=$ at the point of maximum root curvature (a point between D1 and D7)

- $\quad \mathrm{D} 7=7 \mathrm{~mm}$ from the apical foramen

D1 and D7 were determined by locating the apical foramen in the axial view of each specimen and measuring distances of $1 \mathrm{~mm}$ and $7 \mathrm{~mm}$ coronally from this point. Dmc was determined using the "Automatic Snapping of Instruments to Object Surface" Instrument in VGStudioMax. This Instrument was used while observing each specimen in the sagittal view and plotting a line from points D1 to D7 within the relevant canal. When activated, the Instrument snapped automatically from this line to the outermost edge of the arc created by the curvature of the canal (20). This edge was labeled Dmc.

A mean centering ratio in the post-instrumentation canal was calculated by the formula (X1-X2)/Y described by Calhoun and Montgomery (21). The VGStudioMax "Min/Max Distance Tool" Instrument was used to determine the direction of maximum movement between the corresponding canals from Scans 1 and 2 (20). In this formula $\mathrm{X} 1$ represents the maximum extent of canal movement in one direction and $\mathrm{X} 2$ is the movement in the opposite direction, $\mathrm{Y}$ is the diameter of the final canal preparation. These measurements were determined by the superimposition of the preinstrumentation canal over the post-instrumentation canal. Ratios closest to zero indicated a superior centering ability (Fig. 1). 


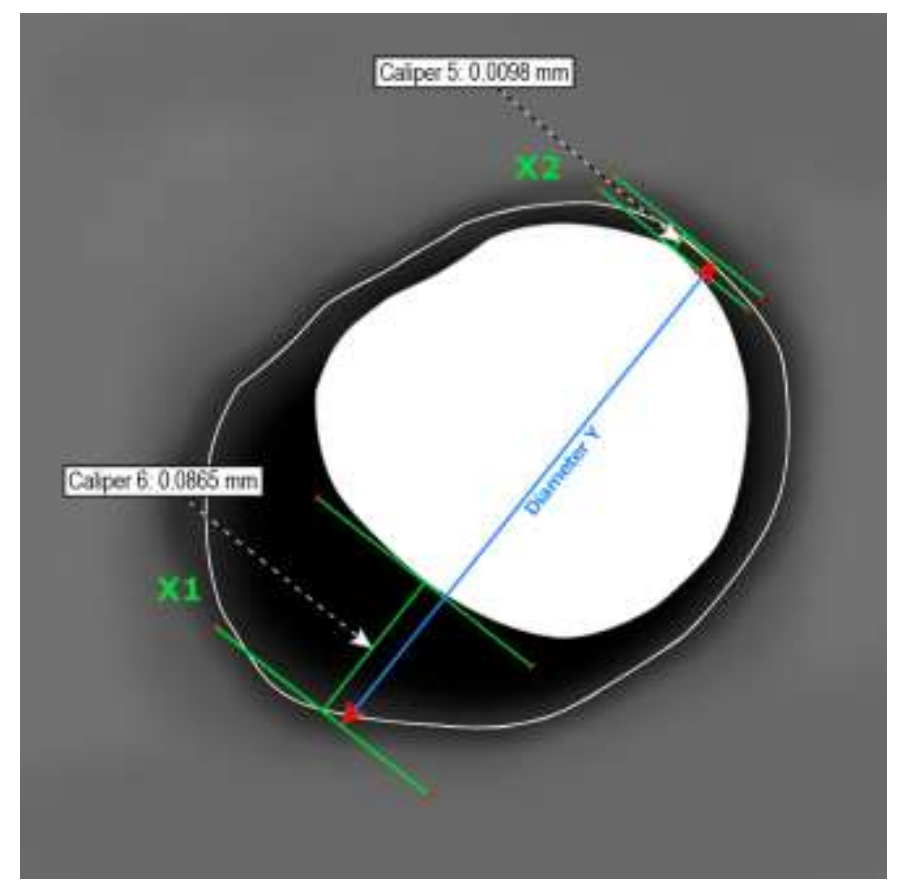

Figure 1.Post-instrumentation canal (shaded black) measurements (X1, X2 and Y) measured from the pre-instrumentation canal (shaded white). In this example, $\mathrm{X} 1$ is in a mesiobuccal direction.

VGStudioMax software was used to evaluate apical canal transportation at D1 using a method described by Bergmans et al (16). A central axis point was located within each pre-instrumentation canal on Scan 1. Using this axis as a reference point, polar co-ordinates were mapped at eight points on the pre-instrumentation canal wall in $360^{\circ}$. The eight points were mapped at $45^{\circ}$ increments in a clockwise rotation mesial (M), mesiobuccal (MB), buccal (B), distobuccal (DB), distal (D), distolingual (DL), lingual (L), mesiolingual (ML).

The co-ordinates mapped within the pre-instrumentation canal images from Scan 1 were then superimposed over the post-instrumentation canal images from Scan 2. In this way the distance between the post-instrumented canal walls and the preinstrumented canal walls were measured in eight directions (Fig. 2) by extending the co-ordinate points determined from Scan 1. Circumferentially equal or similar distances indicated that minimal apical transportation had occurred. Large distances that were concentrated in a few directions were evident of transportation. 


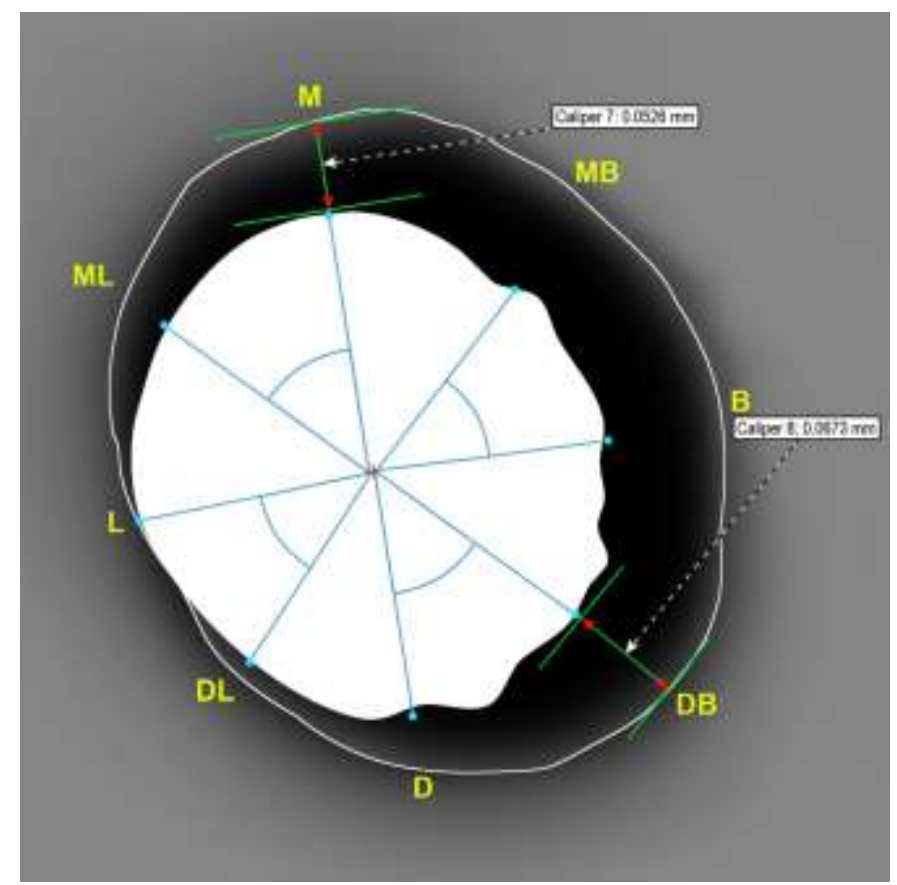

Figure 2. Eight co-ordinates determined in the pre-instrumentation canal (shaded white) superimposed onto the post-instrumentation canal (shaded black) to measure transportation.

\section{Statistical analysis}

Apical canal transportation of the three instrumentation techniques was compared using a one-way Analysis of Variance (ANOVA) $(\mathrm{p}<0.05)$. A Bonferroni adjusted $\mathrm{p}$ value of 0.016 was used in the pairwise comparisons of the mean centering ratios obtained at D1, $\mathrm{D}_{\mathrm{mc}}$, and D7. Significance of differences between the three instrumentation groups was also tested. All statistical procedures were performed on SAS Release 9.3 (SAS Institute Inc., Cary, USA) running under Microsoft Windows (Microsoft Corp., Redmond, Washington) for a personal computer.

\section{Results}

The centering ability of the three glide path instrumentation techniques was compared at D1, Dmc and D7 using ANOVA followed by pairwise comparisons at the Bonferroni adjusted significance $\mathrm{p}$ value of 0.016 . At all $\mathrm{D}$ levels the mean ratios for the stainless steel K-file group were statistically significantly higher than the ProGlider file group. The NiTi rotary glide path file groups displayed statistically similar results at D1. Results at Dmc showed that the ProGlider file produced statistically significant lower mean centering ratios than the other two groups. At D7 there were no statistically significant differences when G-Files and stainless steel Kfiles were compared or when the ProGlider file was compared to G-Files ( $p<0.016$ ). 
Figure 3 illustrates the mean centering ratios of the three glide path instrumentation groups at D1, Dmc and D7 combined.

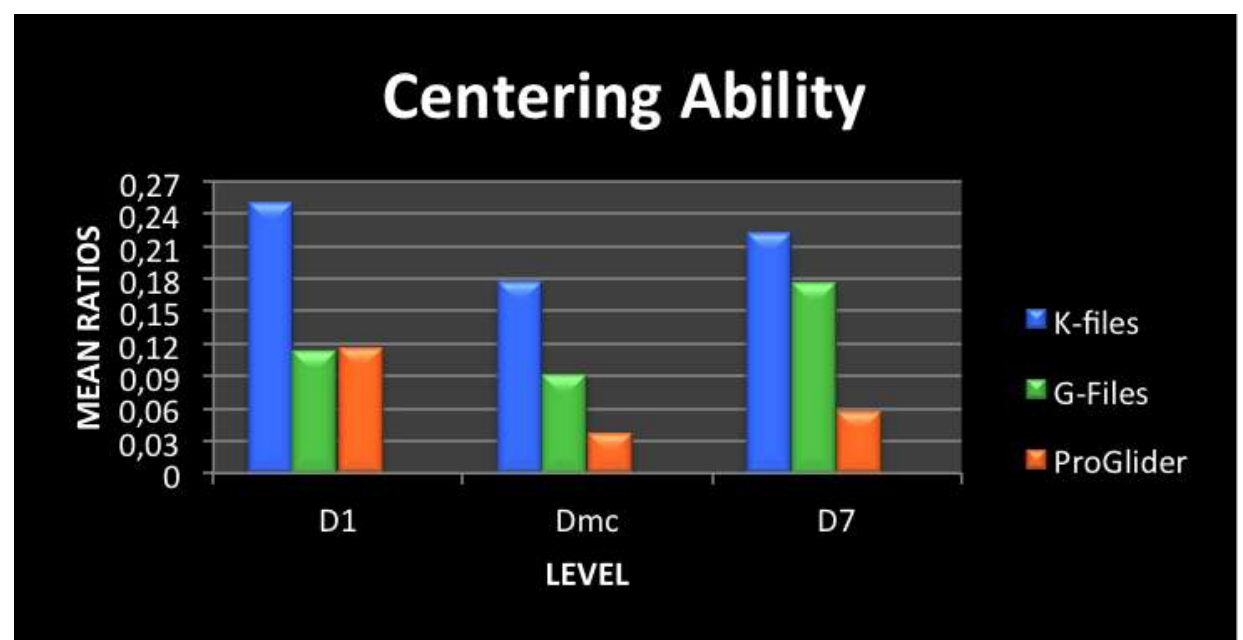

Figure 3. Comparative graph portraying centering ability for the three glide path instrumentation groups at D1, Dmc and D7 (lower mean ratios indicate a favorable centering ability).

Stainless steel K-files were found to transport the canal statistically significantly more than G-Files in five directions: M, MB, B, L, and ML. These two groups exhibited statistically significantly similar apical canal transportation values in the remaining three directions: DB, D, and DL.

The ProGlider file exhibited statistically significantly less apical canal transportation than stainless steel K-files in six directions: M, MB, B, DB, D and ML. Apical canal transportation values for these groups were statistically significantly similar in the remaining two directions: DL, and L. Transportation values for G-Files and the ProGlider file were statistically significantly similar in all directions $(\mathrm{p}<0.05)$.

Table 1 shows the means and standard deviation of apical canal transportation produced by the three instrumentation techniques at D1 of molar root canals instrumented in eight different directions. The results were analyzed using ANOVA. 
TABLE 1:Means \pm (in $\mathrm{mm}$ ) and standard deviation of apical canal transportation produced by each instrumentation technique at D1, according to the direction of dentine removal

\begin{tabular}{lccc}
\hline \multicolumn{1}{c}{ Direction } & \multicolumn{3}{c}{ Technique } \\
\cline { 2 - 4 } & \multicolumn{1}{c}{ K-file } & G-Files & \multicolumn{1}{c}{ ProGlider } \\
\hline Mesial & $0.0763 \pm 0.0488^{\mathrm{a}}$ & $0.0305 \pm 0.0302^{\mathrm{b}}$ & $0.0289 \pm 0.0138^{\mathrm{b}}$ \\
Mesiobuccal & $0.0923 \pm 0.0716^{\mathrm{a}}$ & $0.0306 \pm 0.0360^{\mathrm{b}}$ & $0.0397 \pm 0.0189^{\mathrm{b}}$ \\
Buccal & $0.0703 \pm 0.0509^{\mathrm{a}}$ & $0.0414 \pm 0.0255^{\mathrm{b}}$ & $0.0436 \pm 0.0236^{\mathrm{b}}$ \\
Distobuccal & $0.0572 \pm 0.0288^{\mathrm{a}}$ & $0.0496 \pm 0.0329^{\mathrm{a}, \mathrm{b}}$ & $0.0351 \pm 0.0251^{\mathrm{b}}$ \\
Distal & $0.0653 \pm 0.0465^{\mathrm{a}}$ & $0.0536 \pm 0.0389^{\mathrm{a}, \mathrm{b}}$ & $0.0319 \pm 0.0235^{\mathrm{b}}$ \\
Distolingual & $0.0576 \pm 0.0361^{\mathrm{a}}$ & $0.0553 \pm 0.0361^{\mathrm{a}}$ & $0.0375 \pm 0.0255^{\mathrm{a}}$ \\
Lingual & $0.0530 \pm 0.0306^{\mathrm{a}}$ & $0.0318 \pm 0.0306^{\mathrm{b}}$ & $0.0335 \pm 0.0230^{\mathrm{a}, \mathrm{b}}$ \\
Mesiolingual & $0.0711 \pm 0.0551^{\mathrm{a}}$ & $0.0334 \pm 0.0279^{\mathrm{b}}$ & $0.0312 \pm 0.0186^{\mathrm{b}}$ \\
\hline
\end{tabular}

Mean values with the same superscript letters were not statistically different at $\mathrm{p}<0.05$

\section{Discussion}

This is the first study on curved root canals of extracted human molars to compare the centering ability and apical canal transportation of stainless steel K-files, G-Files and the ProGlider file. No comparative data regarding the centering ability and apical canal transportation for G-Files and the ProGlider file was found in the literature.

Micro-computed tomography was used to evaluate the centering ability and apical canal transportation of the tested groups. It is an easy to repeat method and provides data that allows for the identification of morphologic changes associated with different biomechanical preparations including canal transportation and dentine removal $(22,23)$.

For the examination of centering ability, three levels were chosen: $1 \mathrm{~mm}$ from the apical foramen (D1), the point of maximum root curvature (Dmc) and $7 \mathrm{~mm}$ from the apical foramen (D7). D1 and Dmc represent the apical region and area of maximum curvature, areas that are particularly vulnerable to iatrogenic mishaps $(24,25)$. Results in the present study showed that glide path enlargement with stainless steel K-files was less centered than the NiTi rotary glide path file groups at all levels examined. Statistically similar observations were made for the G-File and ProGlider groups at D1 and D7 $(\mathrm{p}<0.016)$. At Dmc however, the ProGlider group demonstrated significantly better centering ratios than both the G-File and stainless steel K-file groups. This study confirmed the results of previous studies that have demonstrated 
the ability of NiTi rotary glide path files to create more centered root canal preparations than stainless steel K-files $(10,12)$. Results for G-Files in this study, a NiTi rotary glide path file system, however demonstrated a statistically similar centering ability to that of stainless steel K-files at Dmc. The ProGlider file exhibited a superior overall centering ability in comparison to the other groups.

The significant differences in centering ability between the two NiTi rotary glide path file groups at Dmc in this study might be explained by the standard deviation of observations that can occur amongst curved canals of natural teeth, instrument design factors or operational techniques like rotational speed and torque. Curved canals are frequently used as specimens in research studies because these canals present greater challenges to instrumentation $(17,26)$. These challenges have been linked to the observation of performance differences between various instrument systems during the shaping of curved canals $(10,27)$. Statistically, the standard deviation observed when studying canals of natural teeth are higher than those observed in studies using artificial canals. The benefits however that are derived from testing file systems in the natural dentine of extracted teeth is probably greater than those derived from testing in artificial canals $(26,28)$. Natural teeth were used in this study to capitalize on these benefits and make use of the advantages of micro-CT.

The ProGlider file provided a centered preparation and closely maintained the original shape of the curved canal. ProGlider instrument factors that may be relevant include its M-wire construction; variable progressive taper, square cross-section and smaller ISO tip size of 0.16 . The flexibility of an endodontic instrument is influenced by the composition and thermo-mechanical treatment of the metallic alloy as well as by the size of the instrument and its cross-sectional design (29, 30). Flexibility may influence the instrument's ability to properly shape curved root canals. Several studies have shown that more flexible instruments produce more centered preparations (11, 31). The ProGlider file used in this study is manufactured from M-wire NiTi alloy while G-Files are made from conventional NiTi. Heat-treated M-wire alloy has a control memory feature that makes this alloy extremely flexible and more resistant to cyclic fatigue than non-control memory NiTi alloy (32). The performance of G-Files at Dmc in the present study may also be due to the constant $3 \%$ taper or the noncutting tips. The ProGlider file has a semi-active tip with a progressive taper from $2 \%$ to 
8.5\% over its active cutting zone. Differences in the cross-sections of the two NiTi rotary glide path file systems may also contribute to the differences observed at Dmc (33). The ProGlider file has a centered, square cross-section while the cross-section of G-Files has three blades on different radii (Fig. 4).
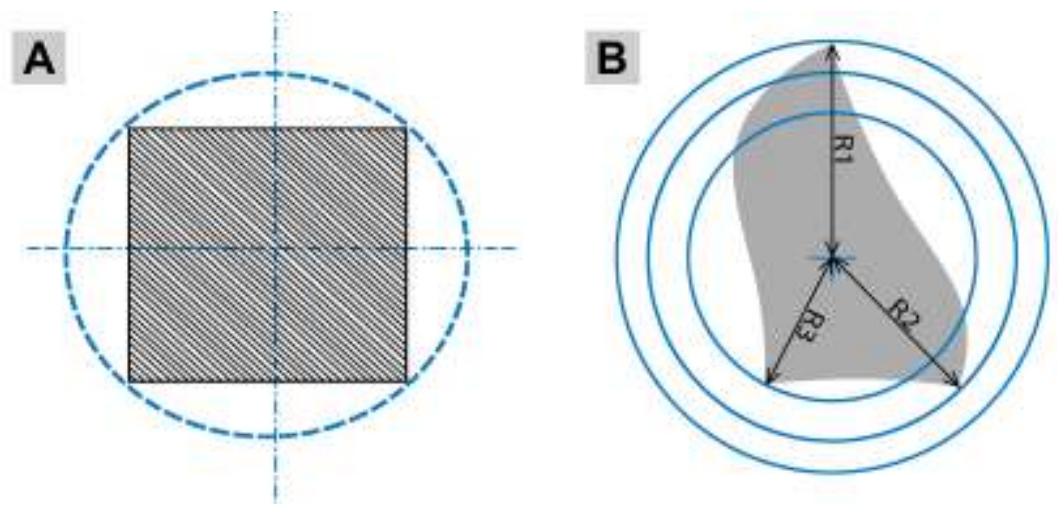

Figure 4. Cross-sections of the rotary files: (A) ProGlider file and (B) G-File.

The results of this study showed statistically similar apical canal transportation mean values for the G-File and ProGlider groups in all directions. Stainless steel K-files were found to transport the canal significantly more than the NiTi rotary glide path file groups in most directions. All three groups exhibited statistically similar transportation in the DL direction $(\mathrm{p}<0.05)$. This observation may be as a result of single operator performing all the enlargements with a possible tendency to instrument towards DL. Further studies may be required to assess the influence of the operator's influence on glide path enlargement outcomes using the systems assessed in our study and in natural human teeth. Many studies have however shown that NiTi rotary glide path file systems tend to transport canals less than stainless steel K-files $(12,34,35)$. The results for apical canal transportation in the present study are in accordance with the results of these studies.

Within the limitations of the present study the following can be concluded: The centering ability of the ProGlider file was favorable at all three levels examined within the instrumented root canals. Overall, apical canal transportation values were more favorable in the NiTi rotary glide path file groups. The ProGlider file and G- 
Files produced statistically similar apical canal transportation values in all directions $(\mathrm{p}<0.05)$.

\section{Acknowledgements}

The authors would like to thank Dentsply Maillefer Co. Laboratories, Ballaigues, Switzerland, for donating the files for this study and the Department of Odontology, University of Pretoria, South Africa for supporting this project. The authors are indebted to The South African National Centre for Radiography and Tomography, Radiation Science, South African Nuclear Energy Corporation for the use of the Micro-Focus X-ray Tomography Facility, particularly Mr. Jakobus W Hoffman for his time and assistance with the reconstruction and analysis of the micro-focus $x$-ray images. The authors would also like to thank Prof. HS Schoeman for his valuable support with the statistical analysis. The authors deny any conflicts of interest related to this study.

\section{References}

1 Berutti E, Negro AR, Lendini M, Pasqualini D. Influence of manual preflaring and torque on the failure rate of ProTaper rotary instruments. J Endod 2004;30(4):228-30.

2 Peters OA, Peters CI. Cleaning and shaping of the root canal system. In: Hargreaves KM, Cohen S, editors. Cohen's Pathways Pulp. 10th ed. St Louis: Mosby; 2010:283348.

3 Peters OA, Koka RS. Preparation of coronal and radicular spaces. In: Ingle JI, editor. Ingle's Endod. 6th ed. Ontario: BC Decker; 2008:877-991.

4 Difiore PM. A dozen ways to prevent nickel-titanium rotary instrument fracture. J Am Dent Assoc 2007;138:196-201.

5 Patino PV, Biedma BM, Liebana CR, Cantatore G, Bahillo JG. The influence of a manual glide path on the separation rate of NiTi rotary instruments. J Endod 2005;31:114-6.

6 Hülsmann M, Peters OA, Dummer PMH. Mechanical preparation of root canals: shaping goals, techniques and means. Endod Top 2005;10:30-76.

7 Knowles KI, Hammond NB, Biggs SG, Ibarrola JL. Incidence of instrument separation using LightSpeed rotary instruments. J Endod 2006;32:14-6.

8 Cassim I, van der Vyver PJ. The importance of glide path preparation in endodontics: a consideration of instruments and literature. South African Dent J 2013;68:322-7.

9 Jerome CE, Hanlon RJ Jr. Identifying multiplanar root canal curvatures using 
stainless-steel instruments. J Endod 2003;29:356-8.

10 Berutti E, Cantatore G, Castellucci A, et al. Use of nickel-titanium rotary pathfile to create the glide path: comparison with manual preflaring in simulated root canals. J Endod 2009;35:408-12.

11 Gergi R, Rjeily JA, Sader J, Naaman A. Comparison of canal transportation and centering ability of twisted files, Pathfile-ProTaper system, and stainless steel hand Kfiles by using computed tomography. J Endod 2010;36:904-7.

12 Pasqualini D, Bianchi CC, Paolino DS, et al. Computed micro-tomographic evaluation of glide path with nickel-titanium rotary PathFile in maxillary first molar curved canals. J Endod 2012;38:389-93.

13 Van der Vyver PJ, Paleker F, Jonker CH. Comparison of preparation times of three different rotary glide path instrument systems. South African Dent J 2015;70:146-9.

14 Nakagawa RKL, Alves JL, Buono VTL, Bahia MGA. Flexibility and torsional behaviour of rotary nickel-titanium PathFile, RaCe ISO 10, Scout RaCe and stainless steel K-File hand instruments. Int Endod J 2014;47:290-7.

15 Rhodes JS, Pitt Ford TR, Lynch JA. A comparison of two nickel-titanium instrumentation techniques in teeth using microcomputed tomography. Int Endod J 2000;33:279-85.

16 Bergmans L, Van Cleynenbreugel J, Wevers M. A methodology for quantitative evaluation of root canal instrumentation using microcomputed tomography. Int Endod J 2001;34:390-8.

17 Schneider SW. A comparison of canal preparations in straight and curved root canals. Oral Surg Oral Med Oral Pathol Oral Radiol Endod 1971;32:271-5.

18 Hoffman JW, De Beer. Characteristics of the micro-Focus x-ray tomography facility (MIXRAD) at Necsa in South Africa. 18th World Conference on Nondestructive Testing. Durban, South Africa; 2012.

19 Volume Graphics GMBH. 3D volume rendering software: VGStudio MAX. Available at: http://www.volumegraphics.com/en/products/vgstudio-max/ct-reconstruction/. Accessed March, 52015.

20 Volume Graphics GMBH. VGStudio 2.2: The leading application software for the visualization of $\mathrm{CT} /$ voxel data. Available at: http://www.volumegraphics.com/fileadmin/user_upload/flyer/VGStudio_22_en.pdf. Accessed March, 52015.

21 Calhoun G, Montgomery S. The Effects of Four Instrumentation Techniques on Root Canal Shape. J Endod 1988;14:273-7.

22 Peters OA, Paqué F. Root canal preparation of maxillary molars with the selfadjusting file: a micro-computed tomography study. J Endod 2011;37:53-7. 
23 Paqué F, Ganahl D, Peters OA. Effects of root canal preparation on apical geometry assessed by micro-computed tomography. J Endod 2009;35(7):1056-9.

24 Jafarzadeh $\mathrm{H}$, Abbott PV. Ledge formation: review of a great challenge in endodontics. J Endod 2007;33:1155-62.

25 Pasqualini D, Alovisi M, Cemenasco A, et al. Micro-computed tomography evaluation of ProTaper next and BioRace shaping outcomes in maxillary first molar curved canals. J Endod 2015;41:1706-10.

26 Alves VO, Bueno CE, Cunha RS, Pinheiro SL, Fontana CE, de Martin AS. Comparison among manual instruments and PathFile and Mtwo rotary instruments to create a glide path in the root canal preparation of curved canals. J Endod 2012;38:117-20.

27 Hülsmann M, Stryga F. Comparison of root canal preparation using different automated devices and hand instrumentation. J Endod 1993;141-5.

28 Setzer FC, Kwon TK, Karabucak B. Comparison of apical transportation between two rotary file systems and two hybrid rotary instrumentation sequences. J Endod 2010;36:1226-9.

29 Tripi TR, Bonaccorso A, Condorelli GG. Cyclic fatigue of different nickel-titanium endodontic rotary instruments. Oral Surg Oral Med Oral Pathol Oral Radiol Endod 2006;102:106-14.

30 Turpin YL, Chagneau F, Vulcain JM. Impact of two theoretical cross-sections on torsional and bending stresses of nickel-titanium root canal instrument models. J Endod 2000;26:414-7.

31 Short JA, Morgan LA, Baumgartner JC. A comparison of canal centering ability of four instrumentation techniques. J Endod 1997;23:503-7.

32 Shen Y, Qian W, Abtin H, Gao Y, Haapasalo M. Fatigue testing of controlled memory wire nickeltitanium rotary instruments. J Endod 2011;37:997-1001.

33 Shen Y, Zhou HM, Zheng YF, Campbell L, Peng B, Haapasalo M. Metallurgical characterization of controlled memory wire nickel-titanium rotary instruments. J Endod 2011;37:1566-71.

34 Glosson CR, Haller RH, Dove SB, del Rio CE. A comparison of root canal preparations using NiTi hand, NiTi motor-driven and K-Flex endodontic instruments. J Endod 1995;21:146-51.

35 Tasdemir T, Aydemir H, Inan U, Ünal O. Canal preparation with Hero 642 rotary NiTi instruments compared with stainless steel hand K-file assessed using computed tomography. Int Endod J 2005;38:402-8. 